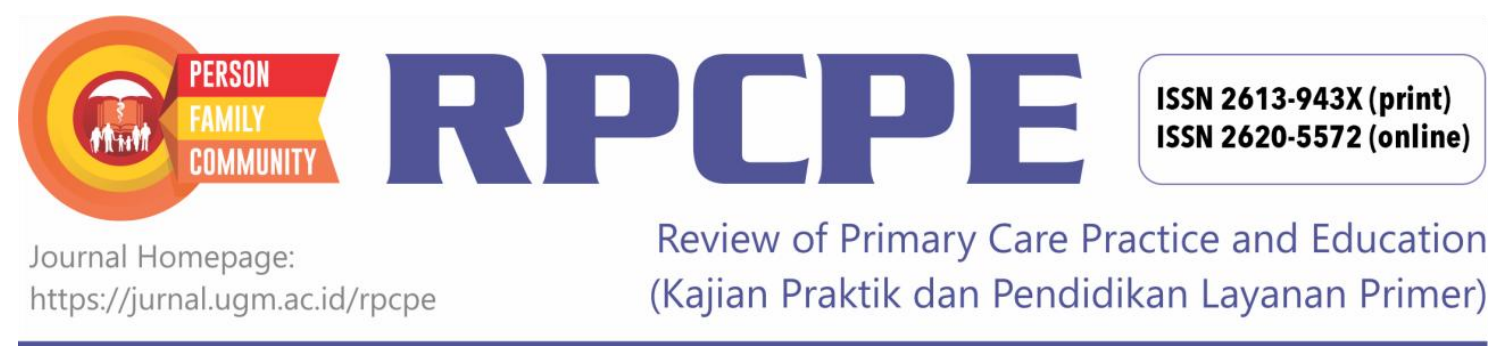

\title{
General Practitioners' Autonomy in the Management of Non-Communicable Diseases (NCDs) in the JKN Era: Is It Feasible?
}

\author{
Nur Afrainin Syah ${ }^{1}$ \\ ${ }^{1}$ Department of Medical Education; Faculty of Medicine; Universitas Andalas; Indonesia \\ Corresponding Author: \\ Nur Afrainin Syah: Department of Medical Education; Faculty of Medicine; Universitas Andalas, Jl. Perintis Kemerdekaan No. 94 \\ Padang, Sumatera Barat - 25127, Indonesia \\ E-mail: nur@med.unand.ac.id \\ To cite this article: \\ Syah NA. General practitioners' autonomy in the management of non-communicable diseases (NCDs) in the JKN era: Is it feasible?. \\ Rev Prim Care Prac and Educ. 2019; 2(3): 89-91.
}

\section{INTRODUCTION}

Demographic, epidemiological, and nutritional transitions increase life expectancy, changes in lifestyles and behaviors of Indonesian people. These changes are resulting in a growing contribution of non-communicable diseases (NCDs) to morbidity and mortality, especially metabolic disorders, such as type 2 diabetes mellitus (DM), hypertension, and dyslipidemia. Approximately $10.9 \%$ of the Indonesian population above 15 years old suffers from type 2 DM (21.2 million) and 34.1\% have hypertension (66.3 million) in 2018. These figures increase significantly from 2013 figure; $6.9 \%$ and $25.8 \%$ respectively ${ }^{1}$. The metabolic disorders, which in turn, are responsible for vascular problems such as renal failure, stroke, and heart attack. Not surprisingly, then, $60 \%$ of Indonesian national health insurance (JKN) funds are spent on the NCDs. This condition causes a deficit and threatens the sustainability of the JKN program.

A comprehensive health care service through peoplecentered integrated care is essential for effective and efficient management of the NCDs. It consists of informing and encouraging people to have a healthy lifestyle, preventing illness; detecting illness as earlier as possible, having the capacity to manage the disease effectively and efficiently; helping patients with rehabilitation and ensuring sensitive palliative care where needed. The people-centered integrated care requires interprofessional collaborative teamwork, in the JKN era, commonly consisting of general practitioners (GPs) in primary care as gatekeepers and internists in secondary services. However, the primary-specialist care interface which is an important organizational feature of the managed care system is often problematic, especially in the management of the $\mathrm{NCDs}^{2}$.

GPs are the primary contact of patients with healthcare services. They have to carefully examine their patients for earlier diagnosis and prompt treatment as well as for deciding whether an internist consultation is needed. A delay in diagnosis, therapy, and referral of a patient to a specialist increases the severity of the NCDs and the potential risk of vascular complications, as well as early disabilities. On the other hand, an unnecessary referral of the NCDs patients to an internist increases the workload of hospital clinics and distract them from patients with more complex NCDs problems. Besides, the unnecessary referral increases waiting time in the hospital clinics, which in turn decreases patient satisfaction and their compliance for the specialist consultation and management. As a result, NCDs patients refuse to be sent to hospitals even though they have vascular complications. Moreover, after having consultation and management in the hospital, the NCDs patients need to be referred back to primary care facilities, in which GPs have to carefully manage those patients so that their diseases are under controlled. In summary, an effective and efficient contribution of GPs as gatekeepers in primary care could contribute to the effective and efficient management of the NCDs, which further could save unnecessary health funding for these degenerative diseases. However, there are still some challenges faced by Indonesian GPs to implement their gatekeeper roles effectively and efficiently.

\section{DISCUSSION}

The health care system, especially its insurance system significantly influences how GPs manage their patients in primary care, including the management of the NCDs. The implementation of universal coverage in 2014, has improved the structure of the Indonesian healthcare delivery system/Badan Penyelenggara Jaminan Sosial Kesehatan (BPJS Kesehatan). The BPJS Kesehatan, a body which manages the universal coverage, enforces an obligation for its members to visit primary care facilities as their first point of contact with the healthcare system. 
Before the implementation of the universal coverage, the majority of the community tended to take specialist private practice and hospital clinics as their first point of contact with the healthcare system and bypassed the GPs' practices. This happened because not many people were members of health insurance at that time so no rules obligated them to visit GPs in primary care facilities. This problem has been remediated by the JKN program.

Even though the implementation of universal coverage has brought a glimmer of hope for GPs to contribute more optimally in healthcare services, there are some limitations imposed by the BPJS Kesehatan policies that could prevent the GPs to work effectively and efficiently. The policies implemented by the BPJS Kesehatan have limited the GPs' professional autonomy and authority, especially in the management of the NCDs. The GPs have to send the NCDs patients to an internist in a hospital clinic to access the chronic medicine package (obat PRB) for those patients. Then, the GPs have to wait for the patients to be sent back by the hospital clinic to continue their management in primary care facilities, using obat PRB prescribed by the specialist. Sometimes, it takes quite long for the patients to be referred back to their GPs. Many of them decide to come back to their GPs by themselves without a letter from their specialist because they are not satisfied with long queues at hospital clinics. The consequence of this patient's refusal to follow the rules of handling chronic illness patients from BPJS is that these patients cannot be registered as patients receiving obat PRB. Management of the NCDs patients in primary care without the aid of obat $P R B$ threatens the effectiveness of treatment because GPs will not be able to prescribe the most appropriate medicine for their patients, due to financial limitations of primary care facilities that are paid for with a capitation system that is also inadequate.

Besides, many newly identified NCDs patients are reluctant to be sent to hospital clinics as required by the BPJS Kesehatan since the beginning. They insist to be managed in the primary care clinic by their GPs. The reasons for these patients are similar to the previous discussion that they do not have time to queue at the hospital the whole day, which makes them unable to work for their living. This patient's refusal also poses a problem for GPs, especially for diagnosing type 2 DM because they cannot send this patient to the clinical laboratory for venous blood sugar testing. As a result, the GPs build the diagnosis of type $2 \mathrm{DM}$ in an unstandardized procedure, which is by using tests of capillary blood sugar. The next consequence is that the GPs manage type 2 DM based on a questionable diagnosis. Hence, GPs do not have the discretion to use clinical laboratory services in their patient care processes. Laboratory services that can be accessed by GPs are only services for patients who are members of the prolanis program (the group of BPJS members with chronic illness). Laboratory services for prolanis members are limited every 6 months, i.e. patients with hypertension and type $2 \mathrm{DM}$ can perform blood chemistry and HbA1C examinations.

Furthermore, the limited access to clinical laboratory examination and other medical procedures make GPs difficult in screening for the NCDs and early detection of their complications. For early detection of chronic illnesses' complications, BPJS Kesehatan has their regimen by requiring the GPs to send their NCDs patients receiving obat $P R B$ every three months to a hospital clinic to have a consultation with a specialist. This policy again increases the number of patients queuing up at the hospital clinic that prevents NCDs patients from coming to the hospital for seeing a specialist. On the other hand, in primary care facilities, GPs cannot do their best for screening their patient's diseases' complications due to their limited access to clinical laboratory examinations and medical procedures.

Finally, there is a contradiction that is showed by BPJS Kesehatan policies. GPs have to control the number of referrals to hospital clinics or specialists as one of their performance indicators as a partner of BPJS Kesehatan. However, the GPs are also forced by the BPJS Kesehatan to make unnecessary referrals as discussed above. The referrals should be prevented if their professional autonomy in patient management is granted by the BPJS Kesehatan by providing adequate access to medicines and laboratory examinations, especially in the management of the NCDs.

Briefly, the implementation of universal coverage which was initially believed could increase GPs' effective and efficient contributions to the health care system, especially in the management of the NCDs, by putting the GPs as the gatekeeper of the system, is far from what was expected. The transformation of health insurance/Asuransi Kesehatan (ASKES) (low coverage and fragmented health insurance system) into BPJS Kesehatan (universal coverage) since 5 years ago does not significantly improve the performance and satisfaction of GPs in managing the NCDs patients because the BPJS Kesehatan implements policies which are similar to ASKES era in terms of insurance company's lack of respect for professional autonomy of the GPs. The GPs perceived that they were controlled and constrained by the health insurance policies in their clinical decision-making process and patient management strategies ${ }^{3}$. Policies implemented by health insurance companies should be in line with professional autonomy. Professional freedom will enable physicians to freely apply their competencies and authorities for the high quality of patient care ${ }^{4,5}$.

Claramita et. al., in World Health Organization - Primary Health Care System study identified that the role of GPs as health care coordinators is not well understood by health policy makers ${ }^{2}$. Hence, they make regulations that do not support the implementation of this role. This results in unclear coordination in healthcare services so that effective and efficient collaboration between primary, secondary and tertiary care cannot be developed. Thus, putting GPs as the gatekeeper of the universal coverage is not sufficient in ensuring the opportunities of GPs to contribute effectively and efficient in providing the best care for the community, without being supported by clear policies for their roles as a care coordinator. Policies that support the roles of GPs 
as a care coordinator in healthcare services in this JKN era are necessary to ensure the implementation of the GPs' professional autonomy for high-quality patient care, especially in the management of the NCDs. Researches are needed to explore how policies that enhance professional autonomy of GPs through ensuring the implementation of their role as care coordinator can support the sustainability of the Indonesian universal coverage.

\section{REFERENCES}

1. Health Research and Development Agency. Basic health research 2018. Jakarta: Ministry of Health Republic of Indonesia. 2018. Available from: http://www.depkes.go.id/resources/download/infoterkini/materi_rakorpop_2018/Hasil\%20Riskesdas\%202018.pdf

2. World Health Organization. Primary health care systems (PRIMASYS): A comprehensive case study from Indonesia. Geneva: World Health Organization. 2017. License: CC BY-NC-SA 3.0 IGO Available from: http://origin.who.int/alliance-hpsr/projects/AHPSRPRIMASYS-Indonesia-comprehensive.pdf

3. Syah NA, Roberts C, Jones A, Trevena L, Kumar K. Perceptions of Indonesian general practitioners in maintaining standards of medical practice at a time of health reform. Family Practice. 2015 Jul 9;32(5):584-90.

4. Kravitz RL, Linn LS, Shapiro MF. Physician satisfaction under the Ontario health insurance plan. Medical Care. 1990 Jun 1:502-12.

5. Williams TV, Zaslavsky AM, Cleary PD. Physician experiences with, and ratings of, managed care organizations in Massachusetts. Medical Care. 1999 Jun 1:589-600. 